\title{
Avaliação da qualidade de vida de produtores de leite do Vale do Taquari
}

\author{
Evaluation of the quality of life of millk producers from Taquari Valley \\ Evaluación de la calidad de vida de los productores de leche en Valle de Taquari
}

\author{
Enzo Vinícius Souza Santana \\ ORCID: https://orcid.org/0000-0002-0977-8682 \\ Universidade do Vale do Taquari, Brasil \\ E-mail: enzo.santana@universo.univates.br \\ Aléxia Rafaela Renz \\ ORCID: https://orcid.org/0000-0002-6988-7768 \\ Universidade do Vale do Taquari, Brasil \\ E-mail: alexia.renz@universo.univates.br \\ Claudete Rempel \\ ORCID https://orcid.org/0000-0001-8573-0237 \\ Universidade do Vale do Taquari, Brasil \\ E-mail: crempel@univates.br \\ Cássia Regina Gotler Medeiros \\ ORCID: https://orcid.org/0000-0001-9466-0437 \\ Universidade do Vale do Taquari, Brasil \\ E-mail: enfmedeiros@univates.br
}

\begin{abstract}
Resumo
Introdução: A qualidade de vida (QV) não tem um conceito ainda totalmente definido, contudo, é possível mensurá-la de diversas formas. Uma das formas de fazer sua avaliação é por meio do questionário WHOQOL-bref, que foi criado pela Organização Mundial de Saúde (OMS). Objetivo: Avaliar a QV de produtores de leite do Vale do Taquari. Metodologia: Foi aplicado o questionário WHOQOL-bref a 108 produtores de leite do Vale do Taquari com o intuito de avaliar os domínios e aspectos que interferem em suas qualidades de vida. Após isso, foi realizada a análise estatística descritiva dos dados obtidos com o questionário. Posteriormente, esses dados foram comparados com outros estudos que também fizeram uso desse questionário. Resultados: A análise desses dados expôs que, embora a média geral aponte, em comparação a outros estudos, como melhores os resultados obtidos no Vale do Taquari, a avaliação de cada domínio de forma independente pode indicar que inúmeros fatores podem ser alterados para melhorar a qualidade de vida dos produtores, principalmente no âmbito psicológico. Conclusão: A aplicação do questionário foi efetiva, tendo em vista que foi possível observar quais parâmetros estão satisfatórios - ou não - no que tange à perspectiva de QV de cada um dos participantes.
\end{abstract}

Palavras-chave: Qualidade de vida; Saúde da população rural; Classificações em saúde.

\begin{abstract}
Introduction: Quality of life $(\mathrm{QoL})$ does not have a fully defined concept yet, however, it is possible to measure it in different ways. One of the ways to make your assessment is through the WHOQOL-bref questionnaire, which was created by the World Health Organization (WHO). Objective: Evaluate the QoL of dairy farmers in Taquari Valley. Methodology: The WHOQOL-bref questionnaire was applied to 108 dairy farmers in Taquari Valley in order to assess the domains and aspects that interfere with their QoL. After that, descriptive statistical analysis of the data obtained with the questionnaire was performed. Later, these data were compared with other studies that also used this questionnaire. Results: The analysis of these data showed that, although the overall average indicates, compared to other studies, the results obtained in Taquari Valley are better, the evaluation of each domain independently may indicate that numerous factors can be changed to improve the QoL of producers, especially in the psychological sphere. Conclusion: The application of the questionnaire was effective, considering that it was possible to observe which parameters are satisfactory - or not - with regard to the perspective of QoL of each of the participants.
\end{abstract}

Keywords: Quality of life; Rural health; Health classifications.

\section{Resumen}

Introducción: La calidad de vida (CV) aún no tiene un concepto completamente definido, sin embargo, es posible medirlo de diferentes formas. Una de las formas de realizar su evaluación es a través del cuestionario WHOQOL-bref, que fue creado por la Organización Mundial de la Salud (OMS). Objetivo: Evaluar la CV de los productores de leche en Valle de Taquari. Metodología: Se aplicó el cuestionario WHOQOL-bref a 108 productores de leche de Valle de Taquari para evaluar los dominios y aspectos que interfieren con su CV. Posteriormente se realizó un análisis estadístico descriptivo de los datos obtenidos con el cuestionario. Posteriormente, estos datos se compararon con otros estudios que también utilizaron este cuestionario. Resultados: El análisis de estos datos expuso que, si bien el 
promedio general apunta, en comparación con otros estudios, los resultados obtenidos en Valle de Taquari son mejores, pero la evaluación de cada dominio de forma independiente puede indicar que numerosos factores pueden modificarse para mejorar la CV de los productores, especialmente en el ámbito psicológico. Conclusión: La aplicación del cuestionario fue efectiva, considerando que fue posible observar qué parámetros son satisfactorios - o no - en cuanto a la perspectiva de CV de cada uno de los participantes.

Palabras clave: Calidad de vida; Salud rural; Clasificaciones en salud.

\section{Introdução}

A Qualidade de Vida (QV) é uma expressão comumente utilizada, mas revestida de grande complexidade, tendo em vista a subjetividade que representa cada pessoa ou grupo social, podendo representar variáveis como a saúde, a família, harmonia, conciliação entre lazer e trabalho, ter liberdade de expressão ou segurança. Ademais, a QV pode ser o resultado de todo esse conjunto de variáveis (Queiroz, Sá, \& Assis, 2004). A QV pode, ainda, pressupor a capacidade das pessoas em sintetizar culturalmente todo o contexto de elementos que determinada sociedade atribui como seu padrão de conforto e/ou bem-estar (Minayo, Hartz, \& Buss, 2000). Com isso, se faz necessário avaliar o contexto histórico, as inúmeras definições e seus diversos meios de avaliação para melhor compreender a QV (Gordia, Quadros, Oliveira, \& Campos, 2011).

Uma forma de transparecer a imprecisão do significado QV é observar as mudanças que a noção da QV vem assumindo ao longo do tempo (Barroso, Lima, Khan, \& Barquete, 2010). Embora os avanços de desenvolvimento e conhecimento na área nos últimos anos sejam notáveis, o conceito de QV ainda não é plenamente estabelecido. Contudo, ao se fazer uma retrospectiva histórica, observamos que, ao tentar avaliar e sintetizar seus fatores, a Organização Mundial de Saúde (OMS) instituiu um grupo composto por experts de culturas distintas (WHOQOL GROUP), onde foram obtidos três aspectos fundamentais da qualidade de vida: a subjetividade; a multidimensionalidade e a presença de dimensões positivas e negativas, de tal modo que o desenvolvimento desses elementos conduziu a definição de qualidade de vida para o WHOQOL GROUP como a percepção do indivíduo de sua posição na vida, no contexto da cultura e sistema de valores nos quais ele vive e em relação aos seus objetivos, expectativas, padrões e preocupações (Fleck et al, 1999).

O grupo desenvolveu ainda o questionário WHOQOL-100 para avaliar a QV. Não obstante, há ainda a versão abreviada do questionário, o WHOQOL-bref, que traz 26 questões, sendo duas questões gerais de QV e as demais 24 representam cada uma das facetas que compõem o instrumento original. Com isso, ao invés de se avaliar cada uma das facetas do WHOQOL-100 por meio de 4 questões, o WHOQOL-bref sintetiza a análise de cada uma das facetas em apenas uma questão (Fleck et al, 2000).

Considerando a ampla variância dos indicadores de QV entre os distintos países, estados ou municípios, se faz importante e necessária a avaliação destes para um maior conhecimento da realidade local. Nesse sentido, ao analisar o contexto do Estado do Rio Grande do Sul (RS), Brasil, destacamos que o Vale do Taquari é uma região composta por 36 municípios, tendo Lajeado como o mais populoso e detentor do maior Produto Interno Bruto (PIB). A região possui 74\% da sua população residindo em áreas urbanas e, portanto, 26\% em áreas rurais e responde por 3,4\% do PIB estadual, sendo que 17,9\% são oriundos da atividade agropecuária, ao passo que Indústria e Serviços respondem por, respectivamente, 30,7\% e $51,54 \%$ do PIB da região (Rio Grande do Sul, 2015).

A atividade agropecuária do Vale do Taquari tem 17,2\% da sua produção econômica oriunda da criação de bovinos de leite e corte. Cabe ressaltar que o Brasil é o $5^{\circ}$ maior produtor leiteiro do mundo e o RS tem papel de destaque no âmbito nacional, sendo o $2^{\circ}$ maior produtor de leite do país (Rio Grande do Sul, 2020). Destaca-se que o trabalho na agricultura é de grande exigência física e que, ao observarmos a população rural da região é factível afirmar que parte desta é idosa. Não obstante, é observável que a população idosa sofre com desgastes e perdem, de forma gradativa, suas propriedades físicas elásticas e a capacidade de resistir às deformidades (Rempel, Haetinger, \& Sehnem, 2013).

Face ao exposto, reconhecendo a relevância do tema, bem como a importância de seu estudo à comunidade científica, 
aos gestores - públicos e privados - e à população em geral, objetivou-se avaliar a QV de produtores de leite do Vale do Taquari.

\section{Metodologia}

Os dados foram obtidos a partir do levantamento transversal junto ao grupo de pesquisa. Para tanto, foram selecionados produtores rurais de todos os municípios do Vale do Taquari. A escolha das propriedades participantes se deu após cálculo estatístico do tamanho amostral que levou em conta a produtividade de cada município, com isso, após contato com a Empresa de Assistência Técnica e Extensão Rural (EMATER) ou com as Secretarias de Agricultura de cada município, foram selecionadas 108 propriedades rurais do Vale do Taquari. Cada uma dessas propriedades teve um produtor rural participante da pesquisa, com médias de idade de 50 anos e idades variando entre 21 e 73 anos.

$\mathrm{O}$ agendamento das visitas às propriedades se deu por meio de contato telefônico, ao passo que a aplicação dos questionários WHOQOL-bref ocorreu, após o preenchimento do Termo de Consentimento Livre e Esclarecido (TCLE), entre os meses de outubro de 2018 e março de 2019. O questionário avalia as 24 facetas preconizadas em sua versão original, o questionário WHOQOL-100, com uma questão de cada uma destas, dividindo-as em quatro domínios, a saber: o domínio físico, com sete questões; o domínio psicológico, composto de seis questões; o domínio social, analisado por meio de três questões e o domínio ambiental, avaliado através de oito questões, totalizando 24 questões. Além das questões específicas relativas aos domínios, temos mais duas questões gerais de qualidade de vida que são analisadas.

$\mathrm{O}$ questionário começa com as duas questões gerais de $\mathrm{QV}$, onde é perguntado como os participantes avaliam sua QV e sua satisfação com a própria saúde. O domínio mais avaliado, o ambiental, é avaliado por meio de questões que envolvem a segurança, finanças, o acesso à informação, o acesso e os meios de transporte, bem como o ambiente físico em si. Já as questões do domínio físico buscam avaliar a dor física, os tratamentos médicos, a disposição, a capacidade de se locomover, o sono, a capacidade de desempenhar atividades cotidianas e de realizar treinos. O domínio psicológico abrange perguntas que avaliam a forma como o participante aproveita a vida, qual o sentido da vida, a capacidade de concentração, a aparência física, a satisfação pessoal e a manifestação de sentimentos negativos dos participantes. Por último, o domínio social, por meio de suas três perguntas, busca avaliar as relações afetivas, interpessoais e o apoio de amigos.

Posteriormente à coleta dos dados por meio dos questionários, foram realizadas as análises estatísticas descritivas, por meio dos softwares BioEstat 5.0 e Microsoft Office Excel ${ }^{\circledR}$, onde foram analisados os aspectos dos domínios social, ambiental, físico e psicológico que influenciam na QV dos produtores analisados, bem como a comparação entre estes, seguindo a sintaxe prevista para a análise dos mesmos. Para a identificação dos aspectos da QV que podem ser melhorados, os dados foram caracterizados qualitativamente, de acordo com a metodologia proposta por Padrão e Sens (2009), que considera a QV 'muito ruim' quando os escores estão entre 0-20; 'ruim' quando estes se encontram entre 21-40; 'nem ruim nem boa' quando entre 41-60; 'boa' se estiverem entre 61-80 e 'muito boa' se os escores estiverem entre 80-100 (Padrão \& Sens, 2009).

Quanto aos aspectos éticos, o projeto foi submetido ao Comitê de Ética em Pesquisa (COEP) da Univates, seguindo todas as diretrizes da Resolução n ${ }^{\circ}$ 466, de 12 de dezembro de 2012, do Conselho Nacional de Saúde, tendo sido aprovado em 19 de março de 2020, conforme parecer consubstanciado no 3.924 .964 .

\section{Resultados e Discussão}

Nas 108 propriedades avaliadas, foi possível observar que o domínio social foi o que obteve resultados mais satisfatórios, isso levando em consideração o fato de tal domínio ter recebido o maior número de classificações 'Muito boa' para a qualidade de vida seguindo a metodologia proposta por Padrão e Sens (2009) (Padrão \& Sens, 2009). Neste contexto, tal afirmação é possível tendo em vista que entre as 108 propriedades, nenhuma recebeu escore 'Muito ruim' ou 'Ruim'; duas 
$(1,85 \%)$ receberam escore 'Nem ruim nem boa'; 46 (42,59\%) receberam escore 'Boa'; e as $60(55,55 \%)$ restantes receberam escore 'Muito boa'.

Em contrapartida, o domínio que recebeu o menor número de classificações 'Muito boa' foi o psicológico, totalizando $21(19,44 \%)$ das 108 propriedades. Por outro lado, obteve o maior número de avaliações 'Boa' para qualidade de vida entre todos os domínios analisados, sendo essas 69, o que representa 63,88\%; 'Nem ruim nem boa' recebeu 18 (16,66\%) avaliações; enquanto as classificações 'Ruim' e 'Muito Ruim' não tiveram nenhuma propriedade avaliada dessa forma.

No que se refere ao domínio ambiental, cada um dos escores 'Muito boa' e 'Boa' recebeu 50 avaliações (46,29\% cada) do total de 108; o escore 'Nem ruim nem boa' recebeu sete, o que representa 6,48\%; o escore 'Ruim' recebeu somente uma $(0,92 \%)$; e o escore 'Muito ruim' não recebeu nenhuma avaliação. Já no que diz respeito ao domínio físico, os resultados obtidos a partir da análise das 108 propriedades foram 38 (35,18\%) classificações 'Muito boa'; 48 (44,44\%) classificações 'Boa'; 21 (19,44\%) classificações 'Nem ruim nem boa'; uma (0,92\%) classificação 'Ruim'; e nenhuma classificação 'Muito ruim'.

Considerando uma análise mais abrangente dos domínios, tem-se que a média de QV referente aos quatro domínios separadamente corresponde à 76,3 para o Domínio Físico; 72,8 para o Domínio Psicológico; 87,0 para o Domínio Social; e 77,4 para o Domínio Ambiental. (Figura 1).

Figura 1 - Média de QV e o desvio padrão de cada domínio avaliado referente aos produtores de leite residentes no Vale do Taquari/RS.

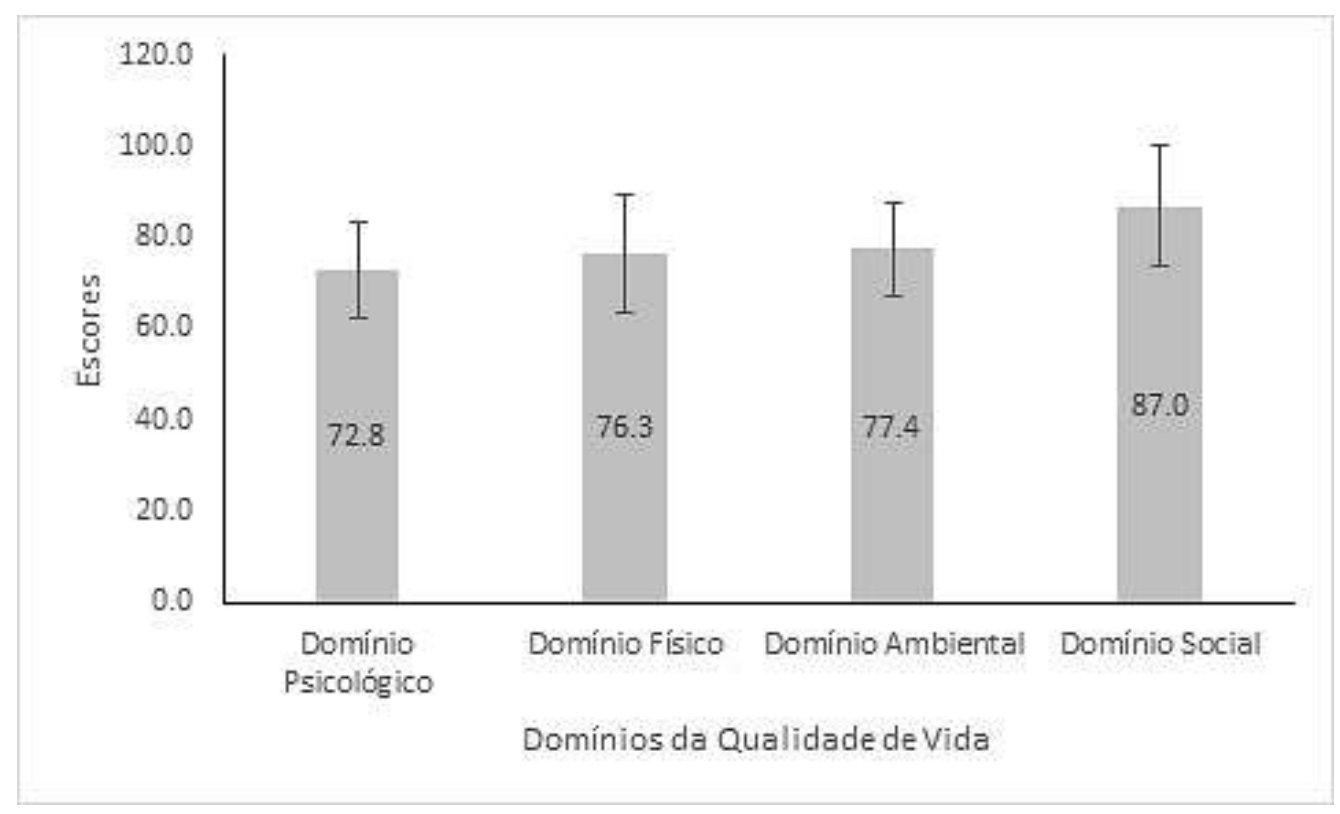

Fonte: Autores.

Para o melhor entendimento, é melhor olhar mais detalhadamente as questões que compõem cada domínio. Nesse sentido, ao realizar uma análise mais aprofundada das questões referentes a cada um dos quatro domínios (físico, psicológico, ambiental e social) presentes no questionário WHOQOL-bref, tem-se um melhor entendimento acerca de quais fatores são mais ou menos incômodos e, consequentemente, mais interferem na qualidade de vida de cada um dos proprietários pesquisados.

Nesse sentido, ao considerarmos o domínio social primeiramente, é possível afirmar que, de uma maneira geral, grande parte dos pesquisados se encontram muito satisfeitos ou satisfeitos com suas relações pessoais (amigos, parentes, 
conhecidos e colegas), com suas relações afetivas e com o apoio recebido por parte de seus amigos. Sendo esses, respectivamente, os temas abordados nas questões 20, 21 e 22 referentes ao domínio social. Tal afirmação pode ser feita tendo em vista que, ao realizar a aplicação do questionário que continha cinco opções de escolha para cada uma das questões, sendo essas: muito insatisfeito, insatisfeito, nem satisfeito nem insatisfeito, satisfeito e muito satisfeito, cada uma delas correspondendo à um número de zero à cinco, os resultados obtidos para as três questões acima citadas revelaram que, quando se trata das relações pessoais, $58(53,70 \%)$ dos produtores se encontram muito satisfeitos; 47 (43,51\%) se mostram satisfeitos; e os outros três $(2,77 \%)$ não estão nem satisfeitos nem insatisfeitos. No que se refere às relações afetivas, $51(47,22 \%)$ estão muito satisfeitos; 50 (46,29\%) estão satisfeitos; já os sete $(6,48 \%)$ restantes se encontram nem satisfeitos nem insatisfeitos. Por fim, tratando-se do apoio recebido por parte dos amigos, os produtores muito satisfeitos são 53 (49,07\%) do total; os que estão somente satisfeitos são 51 (47,22\%); e os quatro (3,70\%) remanescentes são os que não estão nem satisfeitos nem insatisfeitos.

Com relação à pesquisa feita sobre as questões referentes ao domínio psicológico, primeiramente para a questão número cinco que se refere a 'O quanto você aproveita a vida?', os resultados obtidos foram 13 (12,03\%) para 'extremamente'; 43 (39,81\%) para 'bastante'; 43 (39,81\%) para 'mais ou menos'; 9 (8,33\%) para 'muito pouco' e nenhuma para a classificação 'nada'. Em relação à questão seis que questiona 'Em que medida você acha que sua vida tem sentido?', tem-se que 41 (37,96\%) avaliaram como 'extremamente'; 49 (45,37\%) consideraram como 'bastante'; 18 (16,66\%) como 'mais ou menos'; não houve nenhuma avaliação para 'muito pouco' e 'nada'. No que se refere à questão sete 'O quanto você consegue se concentrar?', as classificações 'extremamente' representaram 32 (29,62\%) dos proprietários; 'bastante' representou 34 (31,44\%); 31 (28,70\%) foram as avaliações para 'mais ou menos'; 'muito pouco' representa $11(10,18 \%)$; enquanto isso, 'nada' não recebeu nenhuma avaliação. Tais resultados corroboram com os dados apresentados na Figura 1, que demonstra que o domínio psicológico teve o pior escore de QV. A solidão no meio rural foi retratada em pesquisa realizada com nove idosos (Lorenzo et al, 2019), com o objetivo de saber a percepção dos mesmos sobre o isolamento em meio rural, e permitiu concluir que o isolamento social do idoso no meio rural sofre influência da presença de doenças crônicas e comorbidades (o que também pode ser aplicado a patologias causadas pela grande exigência física e a utilização de agrotóxicos no trabalho rural), que consequentemente compromete a sua autonomia, incita o afastamento dos familiares e amigos e a falta de sensibilização da comunidade a qual eles estão inseridos, além de potencializarem baixa autoestima, falta de bem-estar psíquico e físico. Esta situação tem grande influência na vida dos moradores, impactando em questões psicológicas, que por vezes resulta em depressão e suicídio, que é o tema abordado na pesquisa 'Características epidemiológicas do suicídio no Rio Grande do Sul' (Meneghel, Victora, Faria, Carvalho, \& Falk, 2004), que teve como alvo o elevado padrão de mortalidade por suicídio em regiões fumageiras do RS, além de englobar um estudo ecológico que buscou verificar a relação entre a exposição a agrotóxicos e coeficientes de mortalidade por suicídio. O estudo foi realizado entre os anos de 1980 e 1999, e demonstrou que o RS apresentou os maiores coeficientes de suicídio no Brasil em todos os anos, especialmente entre agricultores, podendo isso ser o reflexo da exposição profissional intensa aos agrotóxicos, que pode acarretar quadros depressivos, por mecanismos neurológicos e/ou endócrinos.

Ainda, para a questão 11, tida como 'Você é capaz de aceitar sua aparência física?', os resultados obtidos foram - para uma escala de 1 a 5, sendo 1 'nada' e 5 'completamente' - 13 (12,03\%) das 108 classificações para 'completamente'; 64 (59,25\%) para 'muito'; e os demais $31(28,70 \%)$ para 'médio'. No que tange a questão 19 , que se trata do quão satisfeita a pessoa está consigo mesma, 48 (44,44\%) dos pesquisados responderam que estão muito satisfeitos; 42 (38,88\%) disseram estar satisfeitos; enquanto os outros 18 (16,66\%) não se encontram nem satisfeitos nem insatisfeitos.

Por último, sobre a questão 'Com que frequência você tem sentimentos negativos tais como mau humor, desespero, ansiedade, depressão?', que corresponde à questão 26 presente no questionário, foi perceptível uma maior variação das respostas obtidas, visto que numa escala de 1 a 5, sendo 1 equivalente à 'nunca'; 2 à 'algumas vezes'; 3 à 'frequentemente'; 4 a 'muito frequentemente'; e 5 a 'sempre', tem-se 5 (4,69\%) das avaliações para 'sempre'; 58 (53,70\%) para 'muito 
frequentemente'; 25 (23,14\%) para 'frequentemente'; $17(15,74 \%)$ para 'algumas vezes'; e somente três $(2,77 \%)$ do total para 'nunca'. Tais resultados corroboram com os dados do estudo 'Mortalidade por suicídio no Rio Grande do Sul: uma análise transversal dos casos de 2017 e 2018' (Franck, Monteiro, \& Limberger, 2020) que analisou as taxas de suicídio para cada 100 mil habitantes a partir do número de casos em cada município e seu tamanho populacional referente a 2017 e 2018 e demonstrou uma necessidade de direcionamento da atenção da Secretaria de Saúde Estadual para algumas regiões, entre elas o Vale do Taquari, pois apresentou, respectivamente 14,8\% e 16,5\% de taxas de suicídio nos anos estudados, sendo estes valores maiores que as médias estaduais, que foram de $11,3 \% \mathrm{em}$ ambos os períodos.

Considerando o domínio ambiental, este que possui o maior número de questões específicas abordadas no questionário WHOQOL-bref e tem por objetivo analisar principalmente a infraestrutura, questões econômicas e de meio ambiente dos proprietários participantes da pesquisa, quando perguntados o quão seguros eles se sentiam em sua vida diária, $39(36,11 \%)$ se sentem extremamente seguros; $47(43,51 \%)$ se encontram bastante seguros; 13 (12,03\%) são os que se sentem mais ou menos seguros; sete $(6,48 \%)$ sendo os que se sentem muito pouco seguros; e os outros dois $(1,85 \%)$ correspondem aos que se sentem nada seguros. No que se refere à quão saudável os proprietários entendiam o seu ambiente físico, se tratando de clima, barulho, poluição e presença de atrativos, as avaliações para um ambiente extremamente saudável foram 73 (67,59\%) do total; os que classificaram o ambiente como bastante saudável representam $28(25,92 \%)$; cinco $(4,62 \%)$ foram os que consideraram o ambiente mais ou menos saudável; e os outros dois $(1,85 \%)$ remanescentes acham o ambiente muito pouco saudável. É perceptível, por meio dos resultados, que a maioria dos moradores do meio rural se sentem seguros e consideram seu ambiente de moradia saudável, o que contrasta com a realidade vista em ambientes mais urbanizados, tendo em vista as altas taxas de criminalidade, além da presença de fatores como poluição e barulho em excesso.

Ainda se tratando do domínio ambiental, foi perguntado aos proprietários 'Você tem dinheiro suficiente para satisfazer suas necessidades?', oito $(7,40 \%)$ representam os que avaliaram como 'completamente'; 45 (41,66\%) sãos os que responderam 'muito' para a questão; 46 (42,59\%) sendo as avaliações para 'médio'; sete $(6,48 \%)$ as referentes a 'muito pouco'; e os dois $(1,85 \%)$ restantes para 'nada'. Referente à disponibilidade de informações necessárias no dia a dia, os que avaliaram como 'completamente' representam $58(53,70 \%)$ do total; as avaliações para 'muito' correspondem a 41 (37,96\%); cinco (4,62\%) são os que responderam 'médio'; e quatro $(3,70 \%)$ os que disseram ser 'muito pouco'. Com isso, percebe-se que os produtores de leite, apesar de morarem na zona rural, estão tendo o devido acesso a informações diárias, visto sua vasta satisfação, o que demonstra que atualmente há uma melhor inclusão digital nas áreas rurais, com a possibilidade de acesso à internet de qualidade, redes de telefone, sinal de televisão e outros meios de comunicação, algo não tão presente em outras gerações, haja visto a grande difusão e expansão tecnológica.

Sobre a questão 'Em que medida você tem oportunidades de atividade de lazer?', as respostas foram 18 (16,66\%) para 'completamente'; 51 (47,22\%) para 'muito'; 22(20,37\%) para 'médio'; 16 (14,81\%) para 'muito pouco'; enquanto 'nada' obteve uma $(0,92 \%)$ avaliação. Podendo estar relacionado com as altas taxas de depressão e suicídio da região, visto que há uma insatisfação com as práticas disponíveis para lazer, com poucas opções de distração além das atividades laborais.

No que concerne às três últimas questões pertencentes ao domínio ambiental, quando perguntado aos proprietários quão satisfeito está com as condições do local onde mora, 74 (68,51\%) respondeu que está muito satisfeito; 30 (27,77\%) diz estar satisfeito; e os outros quatro $(3,70 \%)$ disseram estar nem insatisfeitos nem satisfeitos com as condições do local. Para a pergunta 'Quão satisfeito(a) você está com o seu acesso aos serviços de saúde?', os que responderam estar muito satisfeitos foram 45 (41,66\%); $40(37,07 \%)$ foram os que disseram estar satisfeitos; $12(11,11 \%)$ responderam estar nem insatisfeitos nem satisfeitos; dez $(9,25 \%)$ correspondem aos que estão insatisfeitos; e um $(0,92 \%)$ classificou como muito insatisfeito. Esses dados mostram que aproximadamente 79\% dos produtores de leite estão satisfeitos com o acesso aos serviços de saúde no seu meio, indo contra ao tratado no estudo 'Atenção Primária à Saúde na percepção de mulheres residentes na zona rural' (Pitilin \& 
Lentsck, 2015), realizado nas Unidades Básicas de Saúde (UBS) junto às mulheres residentes na zona rural do município de Prudentópolis/PR, que teve como conclusão a presença de uma má distribuição das Unidades de Saúde e uma escassez de recursos humanos. Assim, pode-se inferir que na região do Vale do Taquari há uma boa cobertura de Unidades de Saúde no meio rural se comparada a região do estudo realizado no Paraná. Ao serem questionados acerca da satisfação do seu meio de transporte, 32 (29,62\%) responderam estar muito satisfeitos; 38 (35,18\%) disseram estar satisfeitos; 29 (26,85\%) são os que dizem estar nem insatisfeitos nem satisfeitos; seis $(5,55 \%)$ correspondem aos que estão insatisfeitos; e os que responderam estar muito insatisfeitos correspondem à três $(2,77 \%)$ participantes. Este resultado sugere que cerca de $35 \%$ dos entrevistados não estão devidamente satisfeitos com o seu meio de transporte, o que pode estar diretamente associado aos cerca de $21 \%$ dos produtores de leite que não estão satisfeitos com o seu acesso à Serviços de Saúde, visto que a falta de um transporte eficiente para o deslocamento até alguma Unidade de Saúde, quando necessário, afeta a qualidade da assistência médica recebida. Além disso, se levarmos em consideração que a prestação de serviços especializados, na maioria das vezes, é realizada em ambiente hospitalar ou em consultórios particulares (Medeiros \& Gerhardt, 2015), percebe-se uma necessidade ainda maior de transporte particular para deslocamentos mais extensos.

Em relação a parte do questionário que se refere ao domínio físico, foi perguntado aos proprietários 'Em que medida você acha que sua dor (física) impede você de fazer o que você precisa?' e 30 (27,77\%) foram os que responderam 'extremamente'; $21(19,44 \%)$ foram as avaliações para 'bastante'; 34 (31,48\%) foram os que classificaram como 'mais ou menos'; as avaliações correspondentes a 'muito pouco' foram 15 (13,88\%); e as oito $(7,40 \%)$ restantes são as respostas referentes a 'nada'. Ao questionar 'O quanto você precisa de algum tratamento médico para levar sua vida diária?' os proprietários que responderam 'extremamente' totalizaram 19 (17,59\%); os que avaliaram como 'bastante' foram 44 (40,74\%); 17 (15,74\%) são os que classificaram como 'mais ou menos'; 19 (17,59\%) representam os que avaliaram como 'muito pouco'; e nove $(8,33 \%)$ as avaliações classificadas como 'nada'. Ao comparar os dados obtidos na pesquisa com o estudo 'Reflexões de idosos sobre as relações entre o trabalho rural, problemas de coluna e postura corporal' [9], é possível inferir que o trabalho rural é de grande exigência física e tem impactos substanciais quando analisadas as queixas álgicas das pessoas, sobretudo em idosos, resultando na grande utilização de tratamento médico para a vida diária. Com relação às queixas álgicas, conforme demonstrado no estudo 'Dor crônica e depressão: estudo em 92 doentes' (Pimenta, Koizumi, \& Teixeira, 2000) que foi desenvolvido entre 1993 e 1994 no Ambulatório do Serviço de Radioterapia do Hospital das Clínicas da Faculdade de Medicina da Universidade de São Paulo, com 92 doentes em tratamento, há uma associação entre dor e estado depressivo, visto que, os doentes com dor apresentaram escores depressivos significativamente mais elevados que os doentes sem dor. Assim, podemos inferir que as pessoas que apresentam dor crônica tendem e podem apresentar distúrbios emocionais, como a ansiedade e até mesmo a depressão.

Ao perguntar aos proprietários 'Você tem energia suficiente para o seu dia a dia?', 34 (31,48\%) foram os que responderam 'completamente'; $43(39,81 \%)$ responderam 'muito'; os que avaliaram como 'médio' representam $26(24,07 \%)$ participantes; enquanto os cinco $(4,62 \%)$ restantes avaliaram como 'muito pouco'. Ainda, foi questionado 'Quão bem você é capaz de se locomover?', 58 (53,70\%) foram os que avaliaram como 'muito bom'; 49 (45,37\%) os que classificaram como 'bom'; enquanto a classificação 'nem ruim nem bom' obteve esse resultado de um participante (0,92\%); não houve nenhuma classificação 'ruim' e 'muito ruim'.

Seguindo nas questões do domínio físico, foi perguntado o quão satisfeitos os proprietários estavam com o próprio sono, e os que disseram estar muito satisfeitos representam 51 (47,22\%) do total; 34 (31,48\%) são os que se encontram satisfeitos; $17(15,74 \%)$ os que não estão nem insatisfeitos nem satisfeitos e seis $(5,55 \%)$ restantes são os que alegam estar insatisfeitos. Sobre como está a satisfação com a própria capacidade de desempenhar as atividades do dia a dia foram 32 $(29,62 \%)$ os que avaliaram estar muito satisfeitos; 53 (49,07\%) disseram estar satisfeitos; 21 (19,44\%) representam os que não 
estão nem insatisfeitos nem satisfeitos; e os dois $(1,85 \%)$ restantes avaliaram como insatisfeitos. No que se refere a satisfação com a própria capacidade para treinar, 26 (24,07\%) alegaram estar muito satisfeitos; os que disseram estar satisfeitos são 56 $(51,85 \%) ; 24(22,22 \%)$ correspondem aos que não estão nem insatisfeitos nem satisfeitos; e dois $(1,85 \%)$ são os que estão insatisfeitos.

Se avaliados os resultados obtidos das duas questões gerais sobre aspectos da QV temos que, ao questionar 'Como você avaliaria sua qualidade de vida?' os que responderam 'muito boa' foram 18 (16,66\%); os que avaliaram como 'boa' foram 64 (59,25\%); já os que avaliaram como 'nem ruim nem boa' foram 24 (22,22\%); enquanto as avaliações para 'ruim' foram duas $(1,86 \%)$; não houve nenhuma avaliação 'muito ruim' para a própria qualidade de vida. Quando perguntado quão satisfeitos estavam com a própria saúde, 34 (31,48\%) foram os que alegaram estar muito satisfeitos; 53 (49,07\%) os que disseram estar satisfeitos; $17(15,74 \%)$ correspondem aos que não estão nem insatisfeitos nem satisfeitos; três $(2,77 \%)$ são os que estão insatisfeitos e apenas um $(0,93 \%)$ respondeu que está muito insatisfeito.

Ao compararmos o gráfico mostrando os resultados da pesquisa sobre os proprietários de leite do Vale do Taquari com os resultados da pesquisa 'Perfil Socioeconômico e Análise da Qualidade de Vida dos Produtores de Leite da Comunidade São Justino, em Juína/MT' (Cavalheiro, Rempel, Laroque, \& Machado, 2014), na qual também foi feita a aplicação do questionário WHOQOL-bref, porém em 20 propriedades agrícolas, não foi possível observar diferença significativa entre os domínios ( $\mathrm{p}=0,1690)$. Sendo a média de $\mathrm{QV}$ do Vale do Taquari a que obteve resultados mais satisfatórios.

Do mesmo modo, ao compararmos com os dados do artigo 'Qualidade de Vida de Trabalhadores Rurais e Agrotóxicos: Um Estudo com o WHOQOL-bref' (Siqueira, 2012) que analisou 343 trabalhadores rurais residentes em dez comunidades de Vitória de Santo Antão/PE, sendo eles divididos em dois grupos: G1, formado por trabalhadores que não utilizavam agrotóxicos e G2, formados pelos trabalhadores que aplicavam agrotóxicos; não foi possível observar diferença significativa no que se refere ao G1 ( $\mathrm{p}=0,0757$ ), no entanto, foi visto que há diferença significativa ao compararmos os resultados da pesquisa feita com o G2 $(\mathrm{p}=0,0194)$. Desse modo, pode-se dizer que há melhores parâmetros da qualidade de vida no Vale do Taquari/RS, quando comparados com os produtores que fazem a utilização de agrotóxicos e residem em Vitória de Santo Antão/PE.

Ainda, após feita a análise dos resultados do artigo 'Qualidade de vida e capacidade funcional de idosos residentes na zona rural' (Tavares, Junior, Dias, Santos, \& Oliveira, 2011), realizado na zona rural do município de Uberaba/MG composto por um total de 850 idosos, foi possível observar que houve diferença significativa quando comparados com os resultados da presente pesquisa, visto que $\mathrm{p}=0,0473$. Demonstrando assim, melhores escores de QV de trabalhadores rurais do Vale do Taquari de diferentes idades à idosos (acima de 60 anos) residentes em Uberaba/MG.

Da mesma maneira, ao compararmos os resultados com a média e o desvio-padrão dos escores da QV da pesquisa 'Qualidade e estilo de vida de produtores de leite em propriedades rurais de um município do Cone Sul de Rondônia' (Moura, Rempel, \& Koetz, 2019), que foi realizada com 42 produtores de leite do município de Vilhena/RO, foi perceptível uma diferença significativa $(\mathrm{p}=0,0017)$, sendo observada uma disparidade nos valores da qualidade de vida de produtores de leite que moram em diferentes estados do país.

\section{Conclusão}

A partir da análise dos resultados obtidos com a pesquisa, percebe-se que a aplicação do questionário WHOQOL-bref - que teve por objetivo mensurar a qualidade de vida dos produtores de leite do Vale do Taquari - foi efetiva, tendo em vista que foi possível, por meio dos quatro domínios, ter uma noção de quais parâmetros estão satisfatórios ou não no que tange a perspectiva de cada um dos pesquisados.

Nesse sentido, foi perceptível que a maior parte dos produtores têm acesso a serviços de saúde de qualidade, além de 
possuir um ambiente físico saudável para estabelecer moradia, com segurança e opções de lazer disponíveis. No entanto, os demais se encontram descontentes com tais aspectos de sua vida. Além disso, viu-se que a maioria dos analisados se encontra contente com as relações pessoais e afetivas no que se refere a amigos, parentes e conhecidos. Por outro lado, há uma insatisfação com o aproveitamento da própria vida, além de uma grande incidência de sentimentos negativos, que são compatíveis com os altos níveis de depressão e suicídio na região do Vale do Taquari/RS. Vale ressaltar que os resultados negativos da pesquisa apresentam características heterogêneas, vindos de diferentes produtores.

No entanto, apesar de alguns aspectos de descontentamento no que se refere às questões presentes em cada domínio, a qualidade de vida de um modo geral continua sendo mais elevada nos produtores de leite do Vale do Taquari se comparada com outros estudos sobre a QV no meio rural.

Importante salientar que o estudo foi feito entre outubro de 2017 até março de 2018, porém, por envolver inúmeras variáveis, os resultados poderiam ser diferentes se a pesquisa tivesse sido feita em outro período, como durante a pandemia do novo coronavírus. Sugere-se, desse modo, que novos trabalhos sejam feitos considerando os dados obtidos durante a pandemia de COVID-19 para avaliar o impacto e a influência da pandemia na qualidade de vida dessa população.

\section{Referências}

Queiroz, C. M. B., Sá, E. N. d. C., \& Assis, M. M. A. (2004). Qualidade de vida e políticas públicas no município de Feira de Santana. Ciência \& Saúde Coletiva, 9(2), 411-421. 10.1590/s1413-81232004000200017

Minayo, M. C. d. S., Hartz, Z. M. d. A., \& Buss, P. M. (2000). Qualidade de vida e saúde: Um debate necessário. Ciência \& Saúde Coletiva, 5(1), 7-18. $10.1590 / \mathrm{s} 1413-81232000000100002$

Gordia, A. P., Quadros, T. M. B. d., Oliveira, M. T. C. d., \& Campos, W. D. (2011). Qualidade de vida: Contexto histórico, definição, avaliação e fatores associados. Revista Brasileira de Qualidade de Vida, 3(1). 10.3895/s2175-08582011000100005

Barroso, L.C.B., Lima, P.V.P.S., Khan, A.S. \& Barquete, P.F.B. (2010, 2020). Projeto de assentamento e qualidade de vida dos produtores rurais: O Caso do Assentamento Santa Bárbara II no Ceará. Congresso da Sociedade Brasileira de Economia, Administração e Sociologia Rural, SOBER, (48), 1-21. Acessado de http://www.repositorio.ufc.br/handle/riufc/3761

Fleck, M. P. d. A., Leal, O. F., Louzada, S., Xavier, M., Chachamovich, E., Vieira, G., Santos, L. d., \& Pinzon, V. (1999). Desenvolvimento da versão em português do instrumento de avaliação de qualidade de vida da OMS (WHOQOL-100). Revista Brasileira de Psiquiatria, 21(1), 19-28. 10.1590/s151644461999000100006

Fleck, M. P.A., Louzada, S., Xavier, M., Chachamovich, E., Vieira, G., Santos, L., \& Pinzon, V. (2000). Aplicação da versão em português do instrumento abreviado de avaliação da qualidade de vida "WHOQOL-bref". Revista de Saúde Pública, 34(2), 178-183. 10.1590/s0034-89102000000200012

Governo do Estado do Rio Grande do Sul. (2015, 2020). Perfil socioeconômico COREDE: Vale do Taquari. Acessado de https://governanca.rs.gov.br/upload/arquivos/201603/17095341-perfis-regionais-2015-vale-do-taquari.pdf

Rio Grande do Sul (2020, 2021). Atlas socioeconômico do rio grande do sul. Acessado de https://atlassocioeconomico.rs.gov.br/inicial

Rempel, C., Haetinger, C., \& Sehnem, E. (2013). Reflexões de idosos sobre as relações entre o trabalho rural, problemas de coluna e postura corporal. Estudos Sociedade e Agricultura, 21(2), 289-307. Acessado de: https://revistaesa.com/ojs/index.php/esa/article/view/369/365

Padrão, M. B., \& Sens, Y. A. S. (2009). Quality of life of living kidney donors in Brazil: An evaluation by the short form-36 and the WHOQOL-bref questionnaires. Clinical Transplantation, 23(5), 621-627. 10.1111/j.1399-0012.2009.01048.x

Lorenzo, Ó., Teixeira, A., Santos, S., Teixeira, D., Penaforte, H., \& Sequeira, C. (2019). Fatores de isolamento social do idoso em meio rural. Revista de Investigação \& Inovação em Saúde, 2(2), 39-46. 10.37914/riis.v2i2.57

Meneghel, S. N., Victora, C. G., Faria, N. M. X., Carvalho, L. A. d., \& Falk, J. W. (2004). Características epidemiológicas do suicídio no Rio Grande do Sul. Revista de Saúde Pública, 38(6), 804-810. 10.1590/s0034-89102004000600008

Franck, M. C., Monteiro, M. G., \& Limberger, R. P. (2020). Mortalidade por suicídio no Rio Grande do Sul: Uma análise transversal dos casos de 2017 e 2018. Epidemiologia e Serviços de Saúde, 29(2). 10.5123/s1679-49742020000200014

Pitilin, É. d. B., \& Lentsck, M. H. (2015). Primary Health Care from the perception of women living in a rural area. Revista Da Escola De Enfermagem Da USP, 49(5), 726-732. 10.1590/s0080-623420150000500003

Medeiros, C. R. G., \& Gerhardt, T. E. (2015). Avaliação da Rede de Atenção à Saúde de pequenos municípios na ótica das equipes gestoras. Saúde em Debate, 39(spe), 160-170. 10.5935/0103-1104.2015s005201

Pimenta, C. A. d. M., Koizumi, M. S., \& Teixeira, M. J. (2000). Dor crônica e depressão: Estudo em 92 doentes. Revista Da Escola De Enfermagem Da USP, 34(1), 76-83. 10.1590/s0080-62342000000100010 
Research, Society and Development, v. 10, n. 13, e493101321518, 2021

(CC BY 4.0) | ISSN 2525-3409 | DOI: http://dx.doi.org/10.33448/rsd-v10i13.21518

Cavalheiro, C. N., Rempel, C., Laroque, L. F. S., \& Machado, B. N. B. (2014). Perfil socioeconômico e análise da qualidade de vida dos produtores de leite da comunidade são justino, em Juína/MT. Revista destaques acadêmicos, 6(3), 148-156. http://www.univates.br/revistas/index.php/destaques/article/view/425

Siqueira, D. (2012). Qualidade de vida de trabalhadores rurais e agrotóxicos: Uma revisão sistemática. Revista Brasileira de Ciências da Saúde, 16(2), 259266. $10.4034 /$ rbcs.2012.16.02.22

Tavares, D. M. S., Junior, S. A. G., Dias, F. A., Santos, N. M. F., \& Oliveira, P. B. (2011). Qualidade de vida e capacidade funcional de idosos residentes na zona rural. Rev Rene, 12, 895-903. https://www.redalyc.org/pdf/3240/324027978002.pdf

Moura, W. N., Rempel, C., \& Koetz, L. C. E. (2019). Qualidade e estilo de vida de produtores de leite em propriedades rurais de um município do Cone Sul de Rondônia. CADERNOS UniFOA, (40), 127-137. Acessado de http://revistas.unifoa.edu.br/index.php/cadernos/article/view/2931/pdf. 